\title{
Differentiated Instruction: Perceptions, Practices and Challenges of Primary School Teachers
}

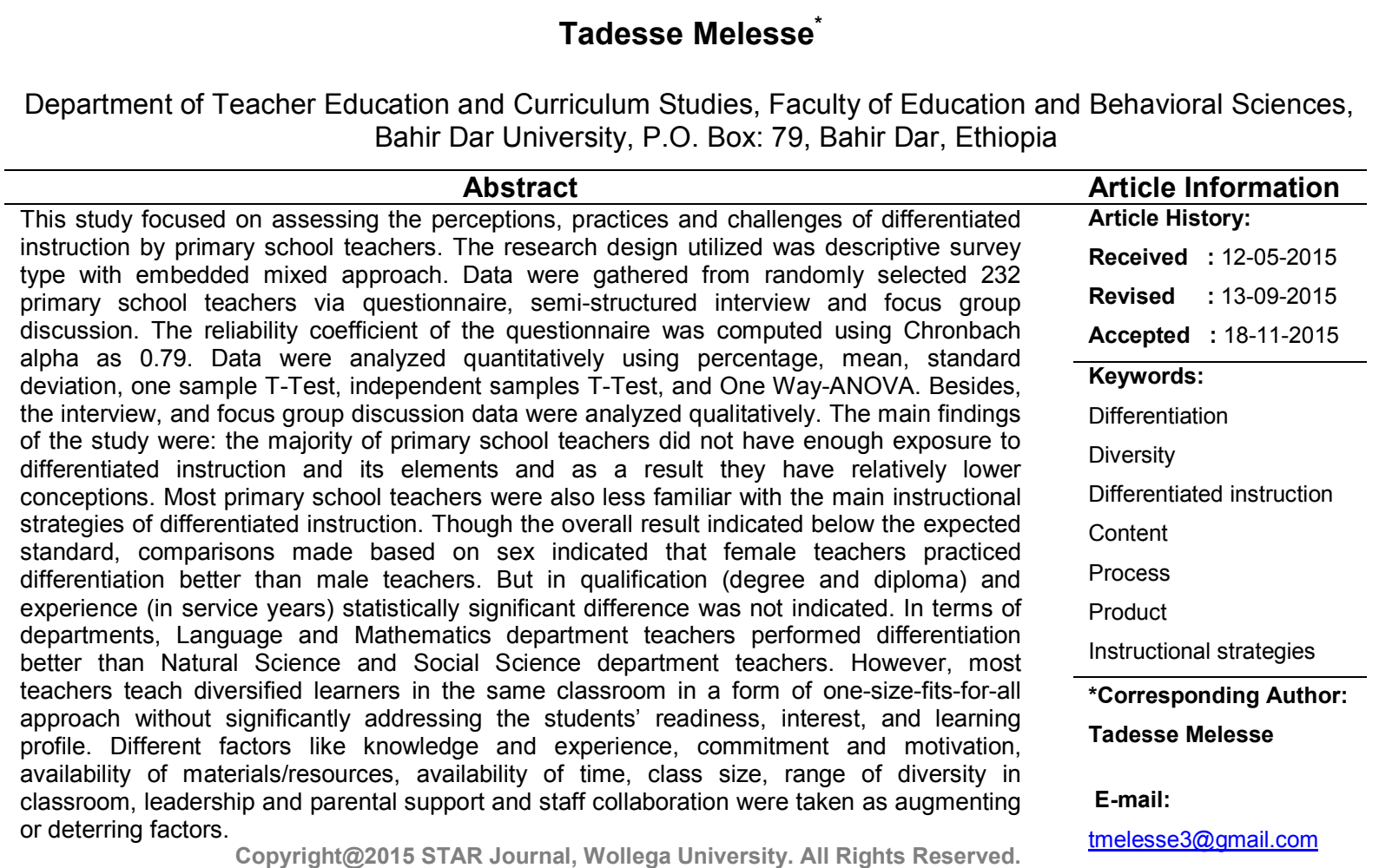

\section{INTRODUCTION}

In the past, educational systems provided students with a general education that was based on established strategies and practices and instruction was teachercentered (Dryden and Vos, 2005; Rodriguez, 2012). Dryden and Vos (2005) for instance, pointed out that many educators throughout the world are still teaching in ways similar to the blackboard-and-chalk, desk-in-rows classroom model. Regardless of the diverse students in the classrooms, curriculum and instruction could be described as a one-size-fits-all treatment (McBride, 2004; Tomlinson, 2006; Willis and Mann, 2000) without addressing learning differences.

Recently schools and educators more than ever, are confronted with the problems of how to accommodate differences or meet needs of individual learners, and how to help them achieve their maximum potential (Jehlen, 2006 in Rodriguez, 2012). Today's classrooms are more diverse than ever, but are ill-equipped to deal with the wide range of student needs (Bantis, 2008; Rodriguez, 2012; Schlechty, 2009). Teachers are teaching in this state of imbalance. Thus, altering schooling and attitudes of teachers into a deep cultural change to address individual learners' needs is crucial (Casey and Gable, 2011). As classroom teachers struggle daily to design learning experiences that serve students' unique abilities, backgrounds, learning styles, and interests, a very practical approach promises to assist them in their questdifferentiated instruction (Ellington and Cardenas, 2007).

Differentiated Instruction (DI) is an approach to teaching and learning that gives students multiple options for taking in information and making sense of ideas (Tomilson and Imbeau, 2010). It is a teaching philosophy based on the premise that teachers should adapt instruction to student differences, because "one size does not fit all" (Heacox, 2009; Tomlinson and Imbeau, 2010; Wormeli, 2007). It addresses learners' variance (Lawrence Brown, 2004; Ireh and Ibeneme, 2010 and Tomlinson, 2003), avoids the pitfalls of the one-size-fits-all curriculum (McBride, 2004); supports the multiple intelligences and varying learning styles (Lawrence- 
Tadesse Melesse

Brown, 2004); and tailors education and curriculum to meet all learners (Caralon and Guinn, 2007).

Many research supports the use of differentiation as a way of meeting the needs of academically diverse learners in today's classrooms (Carolan and Guinn, 2007; Ding and Sherman, 2006; Dunn and Dunn, 2008; Good, 2006; Heck, 2009; Rakow, 2007; Santamaria, 2009; Stronge et al., 2008; Tieso, 2005; Tomilson, 2006; Tomlinson, Brimijoin, and Narvaez, 2008).

Effective DI involves knowing students, understanding the curriculum, providing multiple pathways to learning, sharing responsibility with students and taking a flexible and reflective approach. It is a way for teachers to recognize and react responsively to their students' varying background knowledge, readiness, language, preferences in learning and interests (Hall, 2002; George, 2005; Koutselini, 2006; Smutny, 2003; Tieso, 2003; Tomlinson, 2005).

Research has shown that teachers have a significant effect on academic achievement of students (Ding and Sherman, 2006; Heacox, 2002; Heck, 2009; Marzano, 2007; Phillips, 2010; Rivkin, Hanushek and Kain, 2005; Stronge et al., 2008). Moreover, effective teachers benefit all students regardless of gender, race, or socioeconomic status with quality instruction in primary schools through applying DI (Konstantopoulos, 2009; Rivkin et al., 2005).

In order to address the needs, readiness, interests and learning styles of learners, teachers have to use both teacher based and student based differentiated instruction (Ding and Sherman, 2006; Good, 2006; Heck, 2009; Stronge et al., 2008; Tomlinson, Brimijoin, and Navarez, 2008) With teacher-based differentiation, the teacher can differentiate instruction either through curriculum, content, process, product (what the teacher wants the students to learn), or student differences. The same goes for studentbased differentiation: readiness, interest, learning profile (Good, 2006).

Differentiating can be performed in a variety of ways and if teachers are willing to use this philosophy in their classrooms they opt for a more effective practice that responds to the needs of diverse learners (Tomlinson, 2010). The main instructional strategies utilized to differentiate instruction are: compacting, independent projects, interest centers or interest groups, tiered assignments, flexible grouping, learning centers, varying questions, mentorships, anchoring activities, and learning contracts (Anderson, 2007; Good, 2006; Tomilson, 2006). Based on the above framework, teachers can differentiate instruction: (1) content-what the student needs to learn; (2) process- how the student engages in mastering the content; (3) products-checking how the student achieved the designed goal; and (4) learning environment-the way the classroom works and feels, based on student readiness, interest, or learning profile through applying different instructional strategies- learning contracts, flexible grouping, tiering, learning centers, interest centers, compacting, independent studies, intelligence preferences, varying questions and instructional materials (Tomlinson, 2010).

On the other hand, although studies looking at the effectiveness of DI in addressing specific student needs such as learning styles (Dunn and Dunn, 2008), ability
Sci. Technol. Arts Res. J., July-Sep 2015, 4(3): 253-264

(Tieso, 2005), language (Marin and Franks, 2010) and culture (Santamaria, 2009), little has been done to examine its use by teachers at the elementary school level. Diverse classrooms can pose many challenges and require teachers to develop a variety of activities to help students understand key concepts and make connections to their learning (Hobson, 2004; Keck and Kinney, 2005).

As the case is true in Ethiopia, research also shows that it is much harder for teachers to differentiate instruction based on students' needs, rather they are teaching in a one-size-fits-all approach (Knowles, 2009; Joshi and Verspoor, 2013). As Ethiopia is a multi-lingual, multi-ethnic, multi-cultural country, there needs a practical approach of teaching that tries to address the diversified learners needs and interests. This study therefore aims at assessing the perceptions, practices and challenges of DI by primary school teachers.

Today's schools comprise greater diversity of students in the classrooms (Tomlinson, 2005). Meeting the needs of a diverse student body is one of the most persistent and daunting challenges facing educators in schools (Futrell, Gomez, and Bedden, 2003). Pedagogy has become 'one-size-fits-all' (Alexander, 2008) with a delivery of not addressing the complexity of the learner's needs (Guinier, 2009).

Likewise, Ethiopia's education was entangled with complex problems of relevance, quality, accessibility and equity (TGE, 1994). The long-standing problems associated with the Ethiopian education system were essentially limited and inequitable access, lack of quality and relevance, and continuous decline in quality and standard (MoE, 2002). The absence of interrelated contents and mode of presentation that can develop student's knowledge, cognitive abilities and behavioral changes by level, to adequately enrich problem-solving ability and attitude, were some of the major problems of our education system (TGE, 1994). In formulating the education policy, even though attempts were made in order to make sure that all children, youngsters and adults acquire the competencies, skills, values and attitudes enabling them to participate fully in social, economic and political development of Ethiopia, however, a wider gap remains to address the needs and interests of every learner (MoE, 2010).

Although many effective measures have been taken to maintain quality education, there are critics who claim that, in the name of educational expansion, mediocre education is being sprinkled everywhere like "holy water"(MoE, 2002). Different students with different needs, interests, backgrounds, learning styles, readiness and profiles are learning together the same curriculum by the same teaching-learning methodology in the same classroom. The same assessment procedures and tools, examinations, projects and activities are given for all students of the same classroom based on the principleone-size-fits for all. This has a great effect up on students' academic achievement. Similarly, one of the main challenges explained in ESDP IV is difficulty in improving student achievement and addressing students' special educational needs (MoE, 2010).

To address diversity of learners, curriculum contents and processes should vary and teachers should be trained on how they are addressing students' special 
Tadesse Melesse

educational needs. Similarly, Joshi and Verspoor (2013) portrayed that curriculum implementation should allow for the adequate local knowledge, while avoiding the biases of stereotypes and employing a range of instructional strategies to reach diversified learners. But teachers, as the back bones of any strategy for curriculum implementation, did not use differentiation effectively as a response to students needs by varying the content, process and the product and improve student academic performance (Joshi and Verspoor, 2013).

Furthermore, the researcher with other colleagues provided various trainings on the concept of differentiated instruction for more than 400 primary school teachers being sponsored by SOS Bahir Dar and Bahir Dar University. During such training sessions primary school teachers' exposure to this new approach and the instructional strategies to be applied were not as expected. The trainee teachers' perceptions and practices on this approach and the challenges they mentioned were different for different schools. This triggered the researcher to understand the perceptions, practices, and challenges primary school teachers on differentiated instruction. The intent of this research is therefore, to assess the perceptions, practices and challenges of DI by primary school teachers. Specifically, the study attempted to answer the following research questions (1) What are the perceptions and practices of primary school teachers' about differentiated instruction?, (2) How often do primary school teachers use the instructional/management strategies of differentiated instruction in their classroom?, (3) Is there significant difference in primary school teachers' practice of the overall differentiated instruction as a function of demographic variables (gender, qualification, experience, and departments?, (4) Is there significant difference in primary school teachers' practice of the separate elements of differentiated instruction as a function of demographic variables (gender, qualification, experience, and departments?, (5) What factors help or hinder primary school teachers trying to implement differentiated instruction in the classroom?

\section{MATERIALS AND METHODS}

\section{Research Methods}

The purpose of this study was to assess the practices and challenges of DI by primary school teachers. To this end, descriptive survey research with an embedded mixed methods design that employs primarily a quantitative method and substantiated by qualitative method (Creswell, 2012) was used. An embedded mixed methods design is one in which the quantitative methods supported by the qualitative methods are used to answer research questions in a single study. It is useful to triangulate one set of results with another and thereby enhancing the validity of inferences (Creswell, 2012).

\section{Sources of Data}

Primary school teachers who attended their fifth and sixth years of upgrading summer Post Graduate Diploma in Teaching (PGDT) program at Bahir Dar University in 2013/14 were the main data sources. These primary school teachers who are selected from different departments, faculties and colleges were in two batches. All the sixth year PGDT trainees (first batch) were degree holders whereas the majority of fifth year trainees (second batch) were diploma holders.
Sci. Technol. Arts Res. J., July-Sep 2015, 4(3): 253-264

\section{Samples and Sampling Procedures}

Science college, Social Science faculty and Humanities faculty were selected purposely since it is only in this college and faculties that PGDT training program were provided in the university. From the Science college, Biology, Physics and Mathematics departments were selected randomly. In Social Science faculty, History and Civics and Ethical Education departments and in Humanities faculty, English and Amharic departments were obtained through simple random sampling. Totally, the two batches Post Graduate Diploma in Teaching (PGDT) training program teachers from seven departments were selected randomly and sixty percent of the samples were taken from the total population. When sample teachers were obtained, their demographic variables (gender, qualification, experience, and department) were considered (Table 1).

Table 1: Demographic data of sample primary school teachers attending the PGDT program $(\mathrm{N}=232)$

\begin{tabular}{lcc}
\hline Demographic Category & Frequency $(\mathbf{n})$ & Percentage \\
\hline Gender & & \\
$\quad$ Male & 111 & 47.84 \\
Female & 121 & 52.15 \\
Teaching qualification & & \\
$\quad$ Diploma $\left(2^{\text {nd }}\right.$ batch) & 131 & 56.46 \\
$\quad$ Degree $\left(1^{\text {st }}\right.$ batch) & 101 & 43.53 \\
Teaching experience & & \\
0-5 years & 46 & 19.82 \\
6-10 years & 81 & 34.91 \\
11-15 years & 62 & 26.72 \\
$>15$ years & 43 & 18.53 \\
Current subject areas of & & \\
teaching (department) & & \\
Language & 54 & 23.27 \\
Social Science & 59 & 25.43 \\
Natural Science & 66 & 28.45 \\
Mathematics & 53 & 22.84 \\
\hline
\end{tabular}

At last, proportionate stratified random sampling was used in order to take the actual sample teachers based on their demographic variables.

\section{Data Gathering Instruments}

Data was gathered through questionnaire, interview and focus group discussion.

\section{Questionnaire}

The author used an existing survey questionnaire developed by Tomlinson (2005) and Adlam (2007) cited in Rodriguez (2012) and adapting it into the local contexts. A total of 52 items in the close ended questions of a likerttype scale ranging from 1 (from hardly ever/never) to 4 (almost always) and two items in the open ended questions were involved. The survey involves items that are used to assess teachers' knowledge about differentiation; frequency of times that teachers used DI in specific subject areas; strategies used to apply DI and factors that helped or hindered the implementation of DI.

First, the face validity of the questionnaire was checked by colleagues and one associate professor Besides, it was pilot tested by the non-sample forty-five participants and its reliability was checked using Chrombach alpha as 0.79 . Some items that seem vague for the respondents were rejected and some were improved. 
Interviews and Focus Group Discussion

Semi-structured interviews and focus group discussions were conducted with primary school teachers regarding their knowledge and understandings about differentiation, ways of DI, strategies used to apply DI and factors that helped or hindered the implementation of DI so as to obtain additional data. Interviews with forty-two teachers and focus group discussions with eighteen group members, each group consisting of 4-6 members, were made so as to triangulate the data obtained from the questionnaire.

\section{Data Analysis Techniques}

Both quantitative and qualitative data analysis techniques were employed. Quantitatively, percentage, mean, standard deviation, one sample t-test, independent sample t-test and one-way ANOVA were employed. One sample t-test was used to determine the conceptions and status of primary school teachers' in practicing DI. Whereas, independent sample t-test was used to see gender and qualification difference in the practice of differentiated instruction. One-way ANOVA was used to see the significant difference in primary school teachers' practice of DI based on experience and across departments. On the other hand, the data collected through interview and focus group discussions were analyzed qualitatively through descriptions and narrations.

\section{RESULTS AND DISCUSSION}

In this part of the study the major findings of the study which were categorized into themes were discussed using review of related literature.

The Understandings and Practices of Primary School Teachers Regarding Differentiated Instruction and the Frequency of Utilizing Strategies in their Classrooms

In the first part, teachers were asked about their exposure or training regarding differentiated instruction for the last three or four years of teaching. However, 224 $(96.55 \%)$ teachers reported that training was not provided regarding $\mathrm{DI}$ in any of the courses in their pre-service training programs either from Teacher Training Institutes (TTIs), Colleges, Universities or in in-service trainings, conferences, meetings, or workshops. Therefore, the conception of primary school teachers regarding this concept is low. Consistent to this finding, the finding of Scott (2012) reveled that while much has been written about the theory behind DI, there has been a lack of deep understanding in how to fully implement it. Hobson (2008) also discovered that all of the teachers observed and surveyed reported having very little training on the topic of differentiation. On the same token, Hess (1999) found that "...90\% of teachers do not know how to differentiate instruction in mixed-ability settings". Rodriguez (2012) also revealed that for many teachers, differentiating instruction is a new approach and little is known about teachers' knowledge of DI, how they use it and what factors affect the implementation of differentiated instruction.

Even though $\mathrm{DI}$ in general is a new modality in our country and most primary school teachers were not obtained trainings, however, they are exercising some of the strategies to address students' diversity. In line with this, Hobson (2008) depicted that many teachers in the study were not actually following a model of differentiation, but simply implementing best practices to improve students' achievement. Teachers are of high importance in this regard. Teachers who did not have the differentiation training may have infrequently used the differentiation variables, as evidenced in the student surveys and these random uses of the strategies did not carry over to increased student achievement (Koezye, 2007).

In order to improve students' academic achievement teachers should understand mechanisms of addressing diversified learners' needs since the quality of teachers and their teaching are the most important factors for student outcomes (Barber and Mourshed, 2007; Joshi and Verspoor, 2013; Koezye, 2007). For instance, the research findings of Koezye (2007) portrayed that although achievement was not statistically increased with the use of the other variables, the students in the differentiated classrooms seemed to have a better learning experience than those who were not and were more excited about their work. Emphasizing the importance of teachers up on students' academic achievement, Barber and Mourshed (2007) summarized that "the quality of an educational system cannot exceed the quality of its teachers" $(p, 43)$. Ayalew (2009) also stated that the strength of any educational system largely depends on the quality and commitment of its teachers.

Table 2: One Sample T-Test showing differentiated Instruction ( $\mathrm{N}=232)$

\begin{tabular}{ccccccc}
\hline Variable & Expected Mean & Observed Mean & Mean Difference & df & t & $\boldsymbol{p}$ \\
\hline The status of differentiated instruction & 2.5 & 2.44 & -.052 & 231 & -3.290 & 0.001 \\
\hline & $p<0.05$ &
\end{tabular}

The result of the one-sample t-test analysis shows that the perception of differentiated instruction by primary school teachers was low $(t=-3.290, p<0.05)$. That is, the obtained mean (2.44) is less than the expected mean (2.5). As it is a new concept to our country, about $96.55 \%$ of primary school teachers portrayed that they did not have training on DI and as a result they have low perceptions. Similar findings of Tomilson (2003) also portrayed that as it is a new modality mainly implemented in United States currently, the exposure of teachers in other countries is low. Many researches (Rodriguez's, 2012; Carnine, 2004; Purcell et al., 2002) revealed the same. Even though recent political changes, including increased accountability to state and national standards, have placed an even greater spotlight on differentiation for educators (Carnine, 2004), current practices are apparently not meeting the challenge (Purcell et al., 2002). The result of Hellman (2007) also indicated that teachers' perceptions as to whether or not they were adequately meeting the needs of students in the general education classroom were affected by the differentiated instruction training they received to a statistically significant degree.

Furthermore, primary school teachers were asked about their familiarity of the instructional strategies of DI and the analysis is given below. 


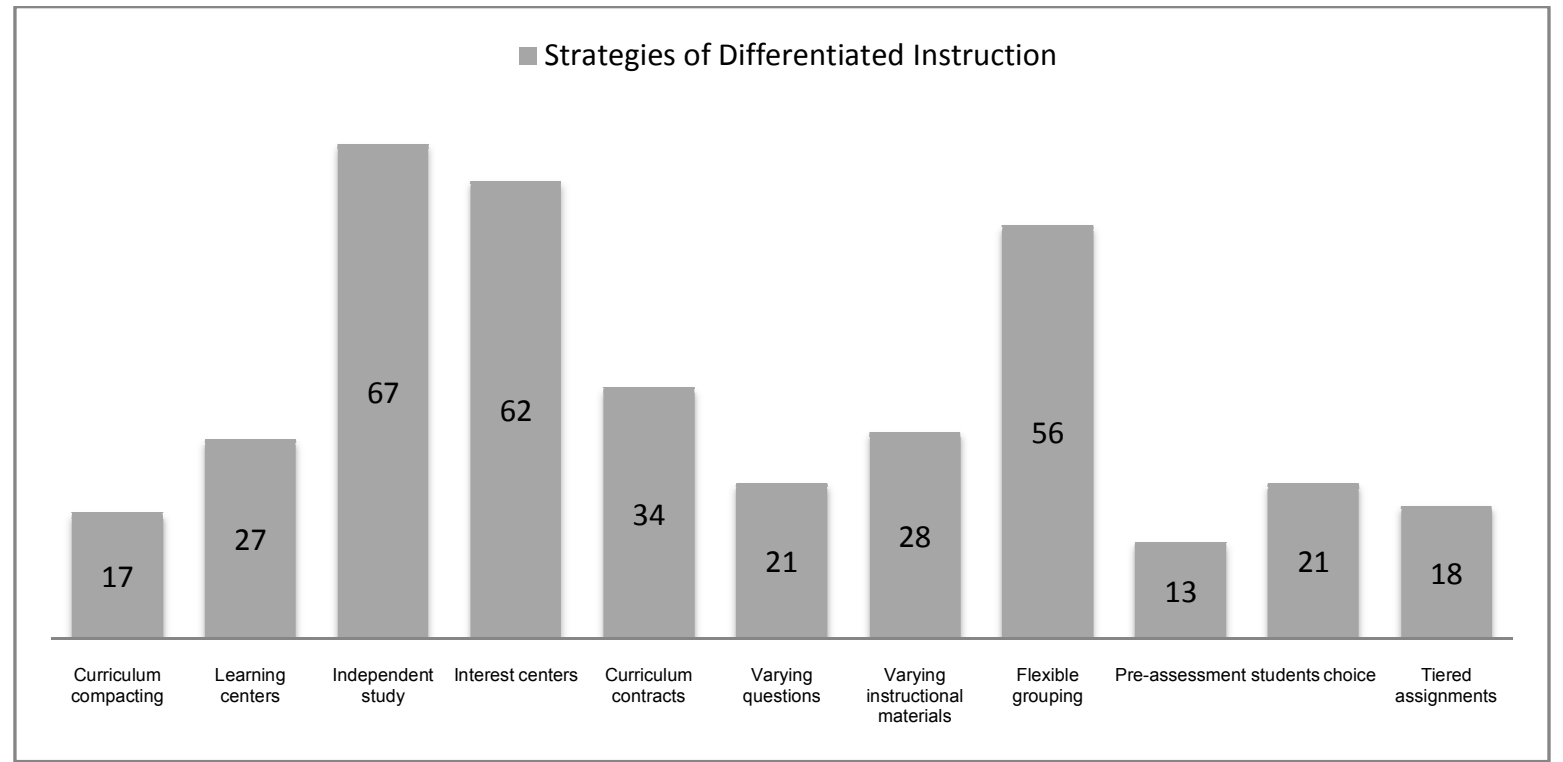

Figure 2: Familiarity of teachers on instructional strategies of $\mathrm{DI}(\mathrm{N}=232)$

The majority of the teachers reported that they were not familiar with most of the presented instructional strategies of DI. However, among the selected eleven strategies of $\mathrm{DI}, 67 \%$ of the primary school teachers revealed that they were familiar with students' independent study. The other $62 \%$ and $56 \%$ also portrayed that they were familiar with interest centers and flexible grouping respectively. Conversely, the least familiar strategies for primary school teachers were preassessment of the learners' performance before the lesson (13\%), curriculum compacting $(17 \%)$, tiered assignments (18\%), students' free choice $(21 \%)$ and varying questions $(21 \%)$. The use of learning centers, varying instructional materials and curriculum contracts were also reported as the least performed strategies by teachers in their classroom practices.

The result of this study showed that the majority of the primary school teachers were not familiar with various strategies of DI. This in turn will have adverse effects up on implementing those strategies in the actual classrooms. Teachers who tried using strategies of differentiation without training lack how to frame students' learning choices, learning styles, interests and learning preferences in the classroom (Koezye, 2007). Thus, quality professional development and the implementation of instructional strategies that address the diverse needs of today's learners are vital and inseparable factors of the educational equation (Chapman and King, 2005).

Though the majority of primary school teachers were less familiar to the strategies of differentiation, however in practice, some teachers exercised few strategies (independent study, interest centers and flexible grouping) better than the other strategies (pre-assessment, compacting, tiering and student free choice). Consistent with this finding, the research finding of Rodriguez (2012) also revealed that of the twelve DI strategies she used, $87 \%$ of the teacher respondents were most familiar with flexible grouping, and $86 \%$ with independent projects or investigations. One difference was that Rodriguez found the independent study to be the least familiar instructional strategy in her study, whereas it was one of the highest familiar strategies in the current study.
In order to implement differentiated instruction, first of all teachers should know and understand their students through pre-assessment data. Pre-assessment data are a strategy teachers are using in order to identify the prior knowledge of students and their gaps. However, familiarity of primary school teachers in this regard was low. In consistent with this finding, teachers practice of pre-assessment, which Levy (2008) revealed, was low. First teachers must know where they are and then how can they are going. Once the students have been preassessed, the teacher must construct an analysis of what is being compared would be made (Emanuelsson and Clarke, 2004; Koezye, 2007). Pre-assessment data drives the instruction in a differentiated classroom (Bondley, 2011). Without pre-assessment data, the teacher would not have the knowledge of what or how to plan for DI. Preassessment techniques were used frequently by the teachers who received differentiation training than from those who did not get training (Koezye, 2007). Besides, Hellman (2007) stated that, primarily, the classroom teacher must be flexible in his/her instruction, procedures, grouping, and assessment. It is only through on-going assessment that the teacher will be able to target the specific needs and interests of the students.

\section{The Frequency of use of Instructional/Management Strategies of DI}

This portion of the study tried to check how frequent teachers are in applying different strategies of differentiated instruction. Among the different types of DI strategies, the majority of teachers were unable to implement pre-assessment data $135(57.44 \%)$, learning centers $133(57.33 \%)$, and curriculum compacting120 (51.72\%). Similarly, 48.27, 43.10, 40.95 and $40.51 \%$ of teachers never utilized tiered assignments, varying questions, varied instructional materials respectively. About $27.65 \%$ of teachers also never addressed students' choice in their classroom delivery. However, one difference was that Rodriguez (2012) found the item provisions for student choice to be a very familiar instructional strategy in her study, whereas it was one of the least familiar strategies in the current study. 
Table 3: The frequency of use of instructional strategies of $\mathrm{DI}$ by teachers in their classroom $(\mathrm{N}=232)$

\begin{tabular}{lcccc}
\hline \multirow{2}{*}{\multicolumn{1}{c}{ DI Strategy }} & Never & Sometimes & Frequently & Always \\
\cline { 2 - 5 } & $\mathbf{n ~ ( \% )}$ & $\mathbf{n}(\%)$ & $\mathbf{n ~ ( \% )}$ & $\mathbf{n ~ ( \% ) ~}$ \\
\hline Use curriculum compacting & $120(51.72)$ & $104(44.82)$ & $8(3.440)$ & - \\
Learning contracts. & $10(4.31)$ & $101(43.53)$ & $91(39.22)$ & $30(12.93)$ \\
Independent study/work. & $14(6.03)$ & $125(53.87)$ & $60(25.86)$ & $32(13.79)$ \\
Interest centers/groups. & $65(28.01)$ & $97(41.81)$ & $58(25)$ & $12(5.17)$ \\
Learning centers/groups & $133(57.33)$ & $84(36.20)$ & $12(5.17)$ & $3(1.29)$ \\
Varying questions & $100(43.10)$ & $111(47.84)$ & $20(8.62)$ & - \\
Varied instructional materials & $95(40.94)$ & $98(42.24)$ & $33(14.22)$ & $6(2.58)$ \\
Flexible grouping & - & $102(43.96)$ & $87(37.5)$ & $43(18.53)$ \\
Pre-assessment data & $135(57.44)$ & $69(29.74)$ & $28(12.06)$ & - \\
Students' choice & $65(27.65)$ & $107(46.12)$ & $46(19.82)$ & $14(6.03)$ \\
Tiered assignments & $112(48.27)$ & $94(40.51)$ & $26(11.20)$ & - \\
\hline
\end{tabular}

Similarly, during my interviews with some of the teachers, they revealed that:

\begin{abstract}
Most of we did not have the know-how of making preassessment in order to check our students' interest, readiness, profile and learning styles. We simply begin to teach the already developed curriculum of the given grade levels and we faced the challenges when we begin assessment and confronting wider gaps in results. Similarly we didn't use curriculum compacting since there is a fixed time schedule for every lesson which we will be checked against by the school principals. Besides, schools didn't have learning centers or classroom areas that contain a collection of activities or materials designed to teach, reinforce, or extend a particular skill or concept of their students.
\end{abstract}

In consistent with this finding, teachers practice of preassessment, which Levy (2008) revealed, was low. To Rodriguez (2012) also the strategies that teachers used least were curriculum compacting but not learning centers. Probably the setting, Rodtiguez conducted her study might have better learning centers which is inconsistent with this finding.

Regarding the varied instructional materials and the tiered assignments teachers are using in their classroom teaching, the other group discussion members also responded that:

Since the curriculum has rigid time schedule and highly structured so we, instead of applying varied instructional materials, are mostly using one and the same instructional material, mainly the text book, for all students learning in one class and the focus is mainly for content coverage. Under this circumstance we could not strictly address diversity and the choices of every student.

\section{They further clarified that:}

Even if we need to use different instructional materials, there is a shortage of the resources. So we are simply keeping our students in the class without ample instructional materials and due to this, students did not have the learning interest. Under many constraints, designing to provide tiered assignments-questions of different levels of complexity, abstractness, and open endedness- in the same class learners is highly ideal and impractical.
On the other hand, to the "sometimes" scale on which teachers applied the instructional strategies, about $53.87 \%$ of teachers rated independent study/work, $47.84 \%$ used varying questions, $46.12 \%$ respected students' choices, $44.82 \%$, utilized curriculum compacting, $43.96 \%$ applied flexible grouping, $43.53 \%$ used learning contracts and $42.24 \%$ used varied instructional materials.

Similar to the above results, the focus group discussants also conjectured that:

We, teachers, are providing for students both individual and group works and we are also organizing 1 to5 groups to support each other. But the group arrangement we are using is not based on their interest, learning style and readiness, rather it is formulated in such a way that one cleaver student is supporting the other five weak students. Sometimes students are also signing contractual agreement with students about their learning but in most cases it is not practical. On the other hand, we are not giving different assignments for different students since it is difficult to compare and judge students in the same way. Teaching out of the planned schedule for us is difficult since we are inspected by the school principals thus how can we implement curriculum compacting under such rigid condition?

For the third scale 'frequently', how frequent they were using the different strategies of DI, about $39.22 \%$ and $37.5 \%$ of teachers respectively rated that they used learning contracts and flexible grouping. The other $25.86 \%$ used independent study. Similar to this finding, flexible grouping was the most common and frequently used by teachers (Rodriguez (2012). Rodriguez also revealed that the most common differentiated instructional strategies used on a daily or weekly basis were varying questions and varied instructional materials. Conversely, the strategy of curriculum compacting, which was not familiar to teachers, was not used very much by them (Rodriguez, 2012).

Even though primary school teachers did not clearly understand which one is a strategy of differentiation they frequently applied some strategies. That is why Pollnow and Tkatchov (2008) stated that DI is a concept most effective teachers have unintentionally done in their classrooms for centuries. Nevertheless, the other strategies of DI were not frequently applied by the majority 


\section{Tadesse Melesse}

of teachers. Because "one size does not fit all," it is imperative that a variety of teaching strategies be used in a differentiated classroom and primary school teachers have to know and apply the different instructional strategies. Of course, in their constructive statements, some interviewees regarding learning contracts put forward that:

“... even though there are inconsistencies in goal setting by students from year to year, the good thing in schools is students set a goal and to achieve that goal teachers are signing learning contracts, written agreements between the teacher, the students and parents that allow the student to work independently and achieve effectively. If students are not performing their tasks properly, students, teachers and parents are accountable.... This has to be continued."

For the last scale, almost all strategies were not applied 'always' by the majority of teachers in their classroom. Generally, the above data vividly indicated that the status of teachers in frequently applying the various instructional strategies was low. These have a significant effect on students' academic achievement (Heacox, 2002; Marzano, 2007; Phillips, 2010; Rivkin, Hanushek and Kain, 2005). Similar findings of the Ministry of Education also confirmed that one of the main challenges in ESDP IV is difficulty in improving student achievement and addressing students' special educational needs (MoE, 2010). Effective teachers benefit all students regardless of gender, race, or socioeconomic status (Konstantopoulos, 2009; Rivkin et al., 2005) and are essential to academic success (Ding and Sherman, 2006; Heck, 2009; Stronge et al., 2008) with high quality instruction throughout primary schools through applying differentiated instruction.
Sci. Technol. Arts Res. J., July-Sep 2015, 4(3): 253-264

Differentiated classroom provides different avenues to acquiring content, processing or making sense of ideas, and developing products. In all contexts, effective DI involves: knowing your students, understanding the curriculum, providing multiple pathways to learning, sharing responsibility with students and taking a flexible and reflective approach. It is a way for teachers to recognize and react responsively to their students' varying background knowledge, readiness, language, preferences in learning and interests (Hall, 2002; George, 2005; Koutselini, 2006; Smutny, 2003; Tieso, 2003; Tomlinson, 2005) in order to assist student learning and their academic achievement (Heacox, 2002).

Differences in Primary School Teachers' Practices of the Overall DI as Function of Demographic Variables

In the overall practice of DI comparisons based on gender (male teachers and female teachers) using Independent Sample T-Test, significant difference was observed $(t=-3.107, p<0.05$ at $d f=230)$. From the result, as compared to male teachers (mean $=124.63$ ), female teachers (mean=129.69) better practiced DI. Though it needs to be further researched, this result might be due to female teachers' skill of handling student's diversified needs and interests more than male teachers as they are mothers.

In contrast to this finding, the research finding of Scott's (2012) study indicated that there was a slight decrease in female test scores from before to after treatment in Mathematics. Male change performance increased $4.09 \%$ after differentiated instructional strategies were implemented in the mathematics instruction. However, Scott (2012) suggested that more study of differentiated instruction and gender would be a good area for further analysis to determine the consistency of this conclusion.

Table 4: Mean differences on the overall practice of differentiated based on gender (Independent Sample T-Test)

\begin{tabular}{cccccccc}
\hline Items & Gender & $\mathbf{N}$ & Mean & SD & t & df & $\boldsymbol{p}$ \\
\hline Overall & Male & 111 & 124.63 & 9.770 & -3.107 & 230 & 0.002 \\
Differentiation & Female & 121 & 129.69 & 14.396 & $p<0.05$ & & \\
\hline
\end{tabular}

Table 5: Mean differences on the overall practice of DI based on qualification (Independent Sample T-Test)

\begin{tabular}{cccccccc}
\hline Items & Qualification & $\mathbf{N}$ & Mean & SD & t & df & $\boldsymbol{p}$ \\
\hline \multirow{2}{*}{ Overall Differentiation } & Diploma & 131 & 126.40 & 14.43595 & -1.192 & 230 & 0.235 \\
& Degree & 101 & 128.39 & 14.76533 & & & \\
\hline \multicolumn{7}{c}{$p>0.05$}
\end{tabular}

Regarding the overall practice of DI comparisons between degree and diploma teachers based on their qualification using Independent Sample T-Test, significant difference was not observed $(\mathrm{t}=-1.192, p>0.05$ at $\mathrm{df}=$ 230). That is, the mean value of degree holders (128.39) is not significantly different from the mean values of diploma holders (126.49). Even though significant difference was not observed due to qualification difference, the research findings of Koeze (2007) indicated that teachers who participated in the DI training reported frequent differentiation in the areas of readiness, interest, flexible grouping, choice, and learning styles.
Whereas, teachers who did not have the differentiation training may have sporadically used the differentiation variables, as evidenced in the student surveys and these random uses of the strategies did not carry over to increased student achievement. Furthermore, the research findings of Tony Mason (1999) cited in Hobson (2008) indicated that teachers in the study discovered a mismatch between what they actually needed to teach students of different ethnic or racial backgrounds and what skills their pre-service programs had prepared them for. 
Table 6: Differences of teachers on the practice of DI based on experience (Summary of One Way-ANOVA)

\begin{tabular}{|c|c|c|c|c|c|}
\hline & Sum of Squares & df & Mean Square & $F$ & Sig. \\
\hline Between Groups & 149.882 & 3 & 49.961 & 0.310 & 0.818 \\
\hline Within Groups & 36704.010 & 228 & 160.983 & & \\
\hline Total & 36853.892 & 231 & & & \\
\hline
\end{tabular}

In comparing the mean values of the overall practice of $\mathrm{DI}$ among teachers based on their experience in teaching using One-way ANOVA $\left.\left(\mathrm{F}_{3,228}\right)=.310, p>.05\right)$, significant difference was not observed among teachers of $0-5$ years of teaching experience, $6-10$ years of experience, 11-15 years of experience, and $>15$ years of teaching experience.

Consistent with the above findings, Hobson's (2008) findings indicated that educational and contextual factors such as years of teaching experience and staff development have no positive effect on how often a teacher differentiates instruction. Similarly, Robison's (2004) findings highlighted that teachers did not relate to any research theory as they related their teaching experiences to the concept of DI. Besides, Hobson's (2008) data showed that the relationships between teachers' years of experience and the number of workshops they attend are not statistically significant in regards to their use of differentiation. However, with respect to the number of college courses attended, the correlation is significant (Hobson, 2008).

Table 7: Differences of teachers based on departments on the practice of DI (Summary of One Way-ANOVA)

\begin{tabular}{|c|c|c|c|c|c|}
\hline & Sum of Squares & df & Mean Square & $\mathbf{F}$ & Sig. \\
\hline Between Groups & 4884.749 & 3 & 1628.250 & 11.612 & 0.000 \\
\hline Within Groups & 31969.143 & 228 & 140.216 & & \\
\hline Total & 36853.892 & 231 & & & \\
\hline
\end{tabular}

Concerning the practice of DI based on department differences, comparisons were made using one wayANOVA. The result of one way-ANOVA $\left(F_{3,228}\right)=.11 .612$, $p<.05)$ indicated that there was a significant difference in the practice of DI among the four departments.

Table 8: Summary of Tukey (HSD) test of Mean comparisons about the practice of $\mathrm{DI}$ among departments $(\mathrm{N}=232)$

\begin{tabular}{llll}
\hline (I) Department & (J) Department & $\begin{array}{c}\text { Mean Diff. } \\
(\mathbf{I}-\mathrm{J})\end{array}$ & Sig. \\
\hline Natural Science & Language & $-9.18013^{*}$ & .000 \\
& Mathematics & $-5.98342^{*}$ & .033 \\
Social Science & Language & $-11.64187^{*}$ & .000 \\
& Mathematics & $-8.44516^{*}$ & .001 \\
& Natural Science & $9.18013^{*}$ & .000 \\
Language & Social Science & $11.64187^{*}$ & .000 \\
& Natural science & $5.98342^{*}$ & .033 \\
Mathematics & Social Science & $8.44516^{*}$ & .001 \\
\hline
\end{tabular}

In order to see the multiple mean differences observed among the four departments, Tukey test or Honestly Significant Difference (HSD) test was employed. From this test of mean comparisons, primary school teachers of Language department (mean=133.57) and Mathematics department (mean=130.37) performed differentiation better than Natural Science (mean=124.39) and Social Science (mean=121.93) department teachers. The reason for the two departments to better perform differentiation was due to more time allocated to these subjects. Consistent to this result, Adlam's (2007) and Rodriguez's (2012) findings revealed that DI was used on a frequent basis in subjects such as Language Arts and Mathematics due to more time allocated to these subjects and due to teachers who teach the same students every day are able to become familiar with each of their student's needs. The t-test result of Hellman (2007) also found that the students who received DI made significant gains in mathematics but not in reading.

Differences in primary school teachers' practices of elements of DI as a function of demographic variables

In response to the realities of diverse student population, many educational leaders, researchers and teacher training programs have made $\mathrm{DI}$ a priority to equip teachers with a knowledge base for understanding and working with the differences that students bring to the classroom (Hobson, 2004; Tomlinson and Imbeau, 2010). Due to this, the study tried to investigate differences in the practice of the elements of DI by primary school teachers as a function of demographic variables.

Table 9: Mean differences on the practice of elements of DI based on gender (Independent Sample t-Test)

\begin{tabular}{|c|c|c|c|c|c|c|c|}
\hline & Sex & $\mathbf{N}$ & Mean & SD & $t$ & df & $p$ \\
\hline \multirow{2}{*}{ Contents } & Male & 111 & 15.67 & 2.71 & \multirow{2}{*}{-1.710} & \multirow{2}{*}{230} & \multirow{2}{*}{0.089} \\
\hline & Female & 121 & 16.28 & 2.75 & & & \\
\hline \multirow{2}{*}{ Process } & Male & 111 & 31.14 & 3.02 & \multirow{2}{*}{-2.276} & \multirow{2}{*}{230} & \multirow{2}{*}{0.024} \\
\hline & Female & 121 & 32.93 & 7.80 & & & \\
\hline \multirow{2}{*}{ Product } & Male & 111 & 12.74 & 3.23 & \multirow{2}{*}{-0.101} & \multirow{2}{*}{230} & \multirow{2}{*}{0.313} \\
\hline & Female & 121 & 13.18 & 3.42 & & & \\
\hline \multirow{2}{*}{ Environment } & Male & 111 & 20.27 & 2.15 & \multirow{2}{*}{.943} & \multirow{2}{*}{230} & \multirow{2}{*}{0.346} \\
\hline & Female & 121 & 20.00 & 2.07 & & & \\
\hline
\end{tabular}


Tadesse Melesse

From the four elements of differentiation (content, process, product and environments), statistically significant difference was observed between male and female primary school teachers in varying the process of differentiation $(t=-2.276, p<0.05$ at $d f=230)$. That is, the mean value of female teachers (32.93) is greater than that of male teachers (31.14). However, significant difference was not detected in terms of contents, products and environment. Effective teachers are expected to apply differentiated instruction by varying contents, methods, products and the learning environment. Not only do teachers interested in DI have to keep in mind student characteristics, they also have to be aware of curricular elements that can be adjusted to match these student differences. So, teachers must consider the key elements that can make a difference in student learning: content, process, product, and learning environment (Hall, 2009; Heacox, 2002; Robinson, 2004; Tomlinson, 2006, 2010; Tomlinson and Eidson, 2003) for a more effective practice that responds to the needs of diverse learners. Thus, ensuring the success of all students through varying the curriculum/ contents, the process, the product and the learning environment is fundamental (Ellington and Cardenas, 2007; Tomlinson, 2010).

In terms of qualification, there was significant statistical difference between diploma and degree holders on the application of contents $(\mathrm{t}=-2.203, p<0.05$ at $\mathrm{df}=230)$, process $(\mathrm{t}=2.142, p<0.05$ at $\mathrm{df}=230)$ and learning environments $(t=-3.230, \quad p<0.05$ at $d f=230)$ as differentiation. The mean comparisons of diploma holders exceeded that of degree holders in content and process differentiation, but in varying environments degree holders mean value exceeded their counterparts. Nevertheless, no significant difference was observed in the variation of products due to qualification difference. Whatever the case, in order to address the readiness, interests and profile of diversified learners, teachers may differentiate instruction based on any one or combination of these elements (Tomlinson, 2006).

Surprisingly, using one way-ANOVA, no significant difference was observed based on teaching experience of primary school teachers in all elements of DI (content, process, product and environments) ( $p>.05)$. On the other hand, departments have shown statistically significant differences in the applications of contents $\left(F_{3}, 228\right)=$ $21.108, p<.05)$ and products $\left.\left(F_{3,228}\right)=20.648, p<.05\right)$ as elements of differentiation. Nevertheless, no difference was observed among departments in terms of process and environments $(p>0.05)$.

Differentiating the content requires that students are pre-tested so teachers can identify students who do not require direct instruction. Those students who demonstrate understanding of the majority of the concepts are not required to participate in direct instruction and may instead use different textbooks with different reading levels, or proceed to apply the concepts to problem solving and enriched or accelerated study. Several strategies like concept-based teaching, curriculum compacting, using varied text and resource materials, learning contracts, mini-lessons, and varied support systems help teachers differentiate content according to students' readiness, interests, and learning profiles (Tomlinson, 2001).
Sci. Technol. Arts Res. J., July-Sep 2015, 4(3): 253-264

Similar to content, process can also be differentiated on the basis of student readiness, interest, or learning profile. Teachers vary process when they provide multiple avenues for students to digest ideas (Tomlinson, 2003). They can provide strategies like tiered activities, providing detailed and specific directions, using graphic organizers, cubing, varying the pace of student work, creative problem solving, and using a variety of criteria for success based on whole-class requirements as well as individual student readiness needs for differentiating the process of learning (Tomlinson and Eidson, 2003; Tomilson, 2003).

Products are the end results of learning (Heacox 2002) and a means by which students demonstrate what they have come to know, understand, and be able to do (Tomlinson and Eidson,2003). It can also be seen at the level of evaluation of students' final work (product), by differentiating the ways and means used to evaluate the learning outcomes of students such as giving students options of how to express required learning; using rubrics that match and extend students' varied skills levels; allowing students to work alone or in small groups on their products; and encouraging students to create their own product assignments as long as the assignments contain required elements.

Differentiation of the learning environment encompasses the ways by which classroom and school environment can be differentiated in order to create a comfortable, friendly and secure environment that supports and promotes the learning effort of students (Smutny, 2003). The classroom's learning environment must be designed to meet the diverse learning needs of the students (Robison, 2004) and considering also other factors affecting learning outside the school borders (Koutselini, 2006). To differentiate learning environment, creating safe classroom that invite student collaboration; providing different resources; promoting independent work; developing routines that allow students to get help when teachers are busy with other students and helping students by understanding them are important (Tomlinson,2006).

Factors Augmenting or Deterring the Implementation of Differentiated Instruction

From the open ended questions teachers filled, the main factors that are enhancing and affecting the implementation of DI were identified.

Knowledge and experience was the top factor identified as the key to facilitating the implementation of $\mathrm{DI}$, and was identified by $93.53 \%$ of the teacher respondents $(n=217)$. The second key facilitating factor identified was commitment and motivation, by $86.20 \%$ $(n=200)$, and the third key factor was availability of materials/resources, by $71.98 \%(n=167)$ of the teachers. The least identified factors were range of student diversity, staff collaboration and availability of time for planning. Teachers who differentiate instruction understand that skillful instruction is an imperative in order to bring curriculum to life for young learners, and flexible instruction is necessary to make curriculum work for academically diverse student populations (Tomlinson and McTighe, 2006). Differentiation is about understanding the needs and abilities of students and providing alternatives within multiple, but manageable constraints (Hall, 2009). 
Table 10: Factors helping teachers to implement differentiated instruction $(\mathrm{N}=232)$

\begin{tabular}{lcc}
\hline \multirow{2}{*}{ Factors } & \multicolumn{2}{c}{ Frequency of Teacher responses } \\
\cline { 2 - 3 } & $\mathbf{n}$ & $\mathbf{( \% )}$ \\
\hline Knowledge and experience & 217 & 93.53 \\
Commitment and Motivation & 200 & 86.20 \\
Availability of materials/resources & 167 & 71.98 \\
Provision of Trainings on DI & 154 & 66.37 \\
School administration, leadership support & 132 & 56.89 \\
Small class size & 132 & 56.89 \\
Parental support & 110 & 47.41 \\
Availability of time for planning & 98 & 42.24 \\
Other staff collaboration & 54 & 23.27 \\
Range of Student Diversity & 40 & 17.24 \\
\hline
\end{tabular}

Teachers and students benefit from a differentiated curriculum. Good teachers should find ways to engage students by tapping into what interests students and by involving them in the daily running of the classroom (Demos and Forshay, 2009; MacGillivray and Rueda, 2001) and understand that each and every student is unique (Tomilson, 2006). It helps teachers consider students' interests and learning styles in planning(Hollas, 2005); allow advanced learners the ability to be challenged and move forward in their learning (Manning, Standford and Reeves, 2010) and enhance their motivation to learn and stay positive (Stronge, 2004; Tomlinson, 2004). Furthermore DI helps creating different pathways to help all students to be successful (Hollas, 2005); take into account learners' differences, needs, and interests (Kelly, 2007); provide for the academic diversity of contemporary classrooms (Blozowich, 2001).

Table 11: Factors Hindering Teachers in Implementing Differentiated Instruction $(\mathrm{N}=232)$

\begin{tabular}{lcc}
\hline \multirow{2}{*}{ Factors } & \multicolumn{2}{c}{ Frequency of Teacher responses } \\
\cline { 2 - 3 } & $\mathbf{n}$ & $\mathbf{( \% )}$ \\
\hline Lack of knowledge and experience & 225 & 96.98 \\
Large class size & 189 & 81.46 \\
Lack of commitment and motivation & 155 & 66.81 \\
Shortage of materials/ resources & 146 & 62.93 \\
Shortage of time & 141 & 60.77 \\
Range of diversity in classroom & 139 & 59.91 \\
Lack of parental support & 137 & 59.05 \\
Lack of school administration support & 118 & 50.86 \\
Traditional outlook of one size-fits-for all & 104 & 44.82 \\
Engaging on routine tasks & 86 & 37.06 \\
Amount of planning time & 66 & 28.44 \\
Lack of Staff collaboration & 34 & 14.65 \\
\hline
\end{tabular}

While implementing differentiated instruction a number of hampering factors were identified. The first hindering factor identified by $225(96.96 \%)$ teachers is lack of knowledge and experience on how to differentiate instruction. The second and third key factors identified were large class size by $189(81.46 \%)$ teachers and lack of interest and commitment as $155(66.81 \%)$ teachers rated respectively. Shortage of materials/resources, shortage of time, range of diversity in classroom, lack of parental support, lack of school administrative support were those hampering factors listed in descending order. The least identified factors were lack of staff collaboration, amount of planning time, engaging on routine tasks and outlook of one size-fits-for all.

Similar to the above findings, lack of knowledge and experience was found to be the main factor affecting teachers in implementing DI. Lack of teacher confidence in managing more flexible classrooms is cited as one barrier to classrooms becoming responsive to the academic needs of diverse learners (Brighton et al., 2004). Thus, teachers have to get the appropriate knowledge through continuous training. Even experienced teachers need access to training and opportunities to network with colleagues (Good, 2006). To Rodriugez
(2012) the key factor that hindered teachers in trying to implement $\mathrm{DI}$ in their classrooms was availability of materials and amount of planning time. According to the findings of Rodriguez the availability of materials was found to both help and hinder the implementation of differentiated instruction.

According to Affholder (2003) time was taken as a critical factor for the implementation of DI, time for lesson planning and preparation, time for collaboration, and a student contact time sufficient for assessment and instruction of students. Many obstacles such as large class sizes, many demands on teachers' schedules, and lack of training on how to differentiate impede even those teachers who are willing to try to improve their practice (Tomlinson, 2001). Lack of staff development, lack of accessible materials, and lack of time to create and implement activities were also other factors (Good, 2006). Besides, pre-existing ideas of how to teach which contradict differentiation, misinformation regarding differentiation, and classroom management skills are areas presented challenges to teachers when attempting differentiation (Casey and Gable, 2011). 


\section{CONCLUSIONS}

Even though practicing it in different ways, most primary school teachers' $(96.55 \%)$ exposure regarding DI through pre-service or in-service trainings for the last three or four years of teaching was low. As a result, their perceptions and practices on DI and its elements were not up to the expectations. Even though some teachers were infrequently and irregularly exercising, the majority of primary school teachers were not familiar with the different instructional strategies of DI (pre-assessment, curriculum compacting, tiered assignments, the use of learner centers, students' free choice, varying questions, varying instructional materials and curriculum contracts).

Despite the fact that the overall status and practice of DI by primary school teachers was low, comparisons on gender indicated that female teachers practiced DI better than male teachers. However, qualification and experience does not indicate statistically significant difference. Departments wise, Language department teachers and Mathematics department teachers performed differentiation better than Natural Science and Social Science department teachers. Lastly, knowledge and experience, commitment and motivation, availability of materials/resources, availability of time, class size, range of diversity in classroom, leadership and parental support and staff collaboration were taken as augmenting or deterring factors for the implementation of differentiated instruction.

\section{Conflict of Interest}

Conflict of interest none declared.

\section{REFERENCES}

Affholder, L.P. (2003). Differentiated instruction in inclusive elementary classrooms. Unpublished EdD thesis. University of Kansas, Kansas.

Alexander, R.J. (2008). Education for all: The quality imperative and the problem of pedagogy. London: Consortium for Research on Educational Access, Transitions and Equity. Research Monograph No 20.

Anderson, K. (2007). Differentiating instruction to include all students. Preventing School Failure 51(3): 49-54.

Ayalew Shibeshi (2009). Secondary School Teacher Deployment in Ethiopia: Challenges and Policy Options for Redressing the Imbalances. In Proceedings of the $16^{\text {th }}$ International Conference of Ethiopian Studies.

Bantis, A.M. (2008). Using task-based writing instruction to provide differentiated instruction for English language learners. (Master's Thesis). Retrieved from ProQuest Dissertation and Theses database. (UMI No. 1454078)

Barber, M., and Mourshed, M. (2007). How the world's bestperforming school systems come out on top. www.ncta.org/p/publications/docs/mckinsey education re port.pdf

Blozowich, D.G. (2001). Differentiated instruction in heterogeneously grouped sixth grade classrooms. (Published thesis - EdD. Immaculate College.

Campbell, B. (2003). Differentiated instruction: resource book. Peterborough, NH: Staff Development for Educators.

Carolan, J., Guinn, A. (2007). Differentiation: Lessons from Master Teachers. Educational Leadership 64(5): 44-47.

Casey Michelle K. and Gable Robert K. (2011). Beginning Teachers' Perceptions of Preparedness to Differentiate Instruction for Diverse Learners. K-12 Education. Paper 4.
Retrieved June 20, 2014 http://scholarsarchive.jwu.edu /k12_ed/4

Creswell, J.W. (2012). Educational Research. Planning, Conducting and Evaluating Research ( $4^{\text {th }}$ ed.). Boston: Pearson Education, Inc.

Denscombe, M. (2008). Communities of Practice: A Research Paradigm for the Mixed Methods Approach. Journal of Mixed Methods Research 2(3): 270-283.

Ding, C., and Sherman, H. (2006). Teaching effectiveness and student achievement: Examining the relationship. Educational Research Quarterly 29(4): 40-51.

Dryden, G. and Vos, J. (2005). The New Learning Revolution. Stafford: Network Educational Press.

Dunn, K. and Dunn, R. (2008). Teaching to at-risk students' learning styles: Solutions based on international research. Insights on Learning Disabilities: From Prevailing Theories to Validated Practices 5(1): 89-101.

Edwards, C.J. Carr, S. and Siegel, W. (2006). Influences of experiences and training on effective teaching practices to meet the needs of diverse learners in schools. Education 126(3): 580-592.

EGRA (2010). Ethiopia Early Grade Reading Assessment Data Analytic Report: Language and Early Learning, USAID Ethiopia.

Ellington, K. and Cardenas, T. (2007) (Authors). Differentiated Instruction Taylor Ranch School's Journey towards Excellence. Professional Development Handbook ( $2^{\text {nd }}$ ed.). Taylor Ranch School, 2500 Taylor Ranch Trail, Venice, Florida 34293, 941.486.2000

Emanuelsson, J. and Clarke, D. (2004). Contrasting comparative research on teaching and learning in mathematics. Proceedings of the 28th Conference of the International Group for the Psychology of Mathematics Education 1: 197-226.

Futrell, M.H., Gomez, J., and Bedden, D. (2003). Teaching the children of a new America: The challenge of diversity. Phi Delta Kappan 84(5): 356-61.

George, P. (2005). A rationale for differentiating instruction in a the regular classroom. Theory Into Practice 44(3): 185103.

Goe, L. (2007). The link between teacher quality and student outcomes: A research synthesis. Washington, DC: National Comprehensive Center for Teacher Quality. Retrieved from http://www.tqsource.org/link.php

Good, M.E. (2006). Differentiated instruction: Principles and techniques for the elementary grades. Unpublished master's thesis, Dominican University of California, San Rafael, California.

Gregory, G.H. and Chapman, C. (2007). Differentiated Instructional Strategies. One size doesn't fit all. Thousand Oaks, CA: Corwin Press.

Guinier, L.( 2009). State of the black union 2009. Public address at the Western Kentucky University, Feb 24.

Hall, B. (2009). Differentiated Instruction, Reaching all students: Research into Practice Mathematics. Pearson Education, Inc. or its affiliate(s)

Hall, T. (2002). Differentiated instruction. Wakefield, MA: National Center on Accessing the General Curriculum. Retrieved July 20, 2014 from http://www.cast.org/ publications/ncac/ncac diffinstruc.html

Heacox, D. (2002). Differentiating instruction in the regular classroom: How to reach and teach all learners, grades 312. Minneapolis, MN: Free Spirit Publishing.

Heacox, D. (2009). Making differentiation a habit: How to ensure success in academically diverse classrooms. Minneapolis, MN: Free Spirit Publishing, Inc. 
Tadesse Melesse

Heck, R.H. (2009). Teacher effectiveness and student achievement. Journal of Educational Administration 47(2): 227-249.

Hobson, M.L. (2008). An Analysis of Differentiation Strategies used by Middle School Teachers in Heterogeneously Grouped Classrooms. A Thesis Submitted to the University of North Carolina Wilmington.

Hollas, B. (2005). Differentiating instruction in a whole-group setting. Peterborough, NH: Crystal Springs Books.

Johnson, B. and Christensen, L. (2008) Educational Research: Quantitative, Qualitative and Mixed Approaches. Los Angeles. SAGE Publications.

Johnston, D.C. (2008). Learning alternatives and strategies for students who are struggling. EP Magazine 8-11.

Joshi, R. and Verspoor, A.(2013). Secondary education in Ethiopia: Supporting Growth and Transformation. Washington DC: The World Bank.

Keck, S. and Kinney, S. (2005). Creating a differentiated classroom. Learning and Leading with Technology 1:1215.

Kelly, D. (2008). Adaptive versus learner control in a multiple intelligence learning environment. Journal of Educational Multimedia and Hypermedia 17(3): 307.

Konstantopoulos, S. (2009). Effects of teachers on minority and disadvantaged students' achievement in the early grades. The Elementary School Journal 110(1): 92-113.

Koutselini, M. (2006). Towards a meta-modern paradigm of curriculum: Transcendence of a mistaken reliance on theory. Educational Practice \& Theory 28(1): 55-69.

Lawrence-Brown, D. (2004). Differentiated instruction: Inclusive strategies for standards-based learning that benefit the whole class. American Secondary Education 32(3): 34-63.

Levy, H.M. (2008). Meeting the needs of all students through differentiated instruction: Helping every child reach and exceed standards. Clearing House 81(4): 161-164.

Marzano, R.J. (2007). The art and science of teaching. Alexandria, VA: Association for Supervision and Curriculum Development.

McBride, B. (2004). Data-driven instructional methods: "Onestrategy-fits-all" doesn't work in real classrooms. $T H E$ Journal 31(11): 38-40

Mertens, D. (2007). Transformative Paradigm Mixed Methods and Social Justice. Journal of Mixed Methods Research 1(3): 212-225.

Minstry of Education (MoE) (2002). The Education and Training Policy and Its Implementation. Addis Ababa.

Phillips, K.J. (2010). What does highly qualifiedll mean for student achievement? Evaluating the relationship between teacher quality indicators and at-risk students' mathematics and reading achievement gains in first grade. The Elementary School Journal 110(4): 464-493.

Pollnow, S. and Tkatchov, O. (2008). High expectations and differentiation equal academic success. ERIC 1: 1-4.

Rakow, S. (2007). All Means All: Classrooms that Work for Advanced Learners. National Middle School Association, Retrieved February 6, 2014, from ERIC database.

Rivkin, S.G., Hanushek, E.A. and Kain, J.F. (2005). Teachers, schools, and academic achievement. Econometrica 73: 417-458.

Robinson, K. (2009). The element: How finding your passion changes everything. New York, NY: Penguin Group, Inc.

Rodriguez, A. (2012). Analysis of Elementary School Teachers' Knowledge and Use of Differentiated Instruction. Dissertations. Paper 39.
Sci. Technol. Arts Res. J., July-Sep 2015, 4(3): 253-264

Santamaria, L. (2009). Culturally responsive differentiated instruction: Narrowing gaps between best pedagogical practices benefiting all learners. Teachers College Record 111(1): 217-247.

Santangelo, T. and Tomlinson, C. (2009). The application of differentiated instruction in postsecondary environments: Benefits, challenges, and future directions. International Journal of Teaching and Learning in Higher Education, 20(3): 307-323.

Schussler, D.L. (2009). Beyond Content: How teachers manage classrooms for facilitate intellectual engagement for disengaged students. Theory into Practice 48:114-121

Scott, B. (2012). The Effectiveness of Differentiated Instruction in the Elementary Mathematics Classroom. Doctor of Elementary Education Degree Thesis. Ball State University Muncie, Indiana, March 2012.

Sternberg, R. (1985). Beyond IQ: A Triarchic theory of human intelligence. Cambridge, MA: Cambridge University Press.

Stronge, J. (2002). Qualities of effective teachers. Alexandria, VA: Association for Supervision and Curriculum Development.

Stronge, J.H., Ward, T.J., Tucker, P.D., and Hindman, J.L. (2008). What is the relationship between teacher quality and student achievement? An exploratory study. Journal of Personnel Evaluation in Education 20: 165-184.

Transitional Government of Ethiopia (TGE) (1994). The Education and Training Policy of Ethiopia. Addis Ababa.

Tieso, C. (2003). Ability grouping is not just tracking anymore. Roper Review 26: 29-36.

Tobin, R. (2008). Conundrums in the Differentiated Literacy Classroom. Reading Improvement 45(4): 159-169.

Tomlinson, C.A. (2006). Differentiated instructions for academic diversity. U.S.A: J. M. Cooper

Tomlinson, C.A. (2005). Deciding to differentiate instruction in middle school: One School's Journey. Gifted Child Quarterly 39(2): 77-87.

Tomlinson, C.A. (2003). Differentiation into practice. A resource guide for differentiating curriculum, grades $K-5$. Alexandria, VA: Association for Supervision and Curriculum Development.

Tomlinson, C.A. (2002). Invitations to learn. Educational Leadership 60(1): 6-10.

Tomlinson, C. A. (2001). Differentiated instruction in the regular classroom. Understanding Our Gifted, 14(1):3-6.

Tomlinson, C.A. (2000). Differentiation of instruction in the elementary grades. Champaign, IL: ERIC Clearinghouse on Education and Early Childhood Education. (ERIC Document Reproduction Service No. ED443572).

Tomlinson, C.A. (1999). The differentiated classroom: Responding to the needs of all learners. Alexandria, VA: Association for Supervision and Curriculum Development.

Tomlinson, C.A., Brimijoin, K., and Narvaez, L. (2008). The differentiated school: Making revolutionary changes in teaching and learning. Alexandria, VA: Association for Supervision and Curriculum Development.

Tomlinson, C. and Eidson, C. (2003). Differentiation in Practice: $A$ resource guide for differentiating curriculum, Grades K-5.Alexandria, Virginia: Association for Supervision and Curriculum Development.

Tomlinson, C.A. and Imbeau, M. (2010). Leading and Managing a Differentiated Classroom. Alexandria Virgina: ASCD.

Wormeli, R. (2007). Differentiation: From planning to practice, grades 6-12. Portland, ME: Stenhouse Publishers. 